\title{
HORMONAL INFLUENCES ON THE TIME OF OVULATION IN THE RABBIT AS DETERMINED BY LAPAROSCOPY
}

\author{
S. FUJIMOTO,* J. M. R. RAWSON AND W. R. DUKELOW \\ Endocrine Research Unit, Michigan State University, \\ East Lansing, Michigan 48823, U.S.A.†
}

(Received 30th July 1973)

\begin{abstract}
Summary. The technique of laparoscopy was modified for use in the rabbit and was found to facilitate continuous observation of follicular development and ovulation. The timing of ovulation was studied and suggests that 100 i.u. HCG, whether used in a superovulation regimen or solely as an ovulatory stimulus, causes a greater ovulation rate than does a mating stimulus. Follicular rupture was observed and frequently occurred in the smaller follicles first. Laparoscopy in pregnant rabbits suggests that quantification of preimplantation blastocysts is not only possible but also very accurate and is without deleterious effects on the developing embryos. These results suggest that the laparoscopic technique may be a valuable asset to the study of reproductive phenomena in the rabbit.
\end{abstract}

\section{INTRODUCTION}

The recent application of laparoscopy to ovulation examination, ovarian biopsy, oviducal ligation and clinical diagnosis of various reproductive disorders reflects the pioneering efforts of Semm (1969) and Balin, Wan \& Rajan (1969). Previous reports have shown that ovulation in the rabbit occurs as

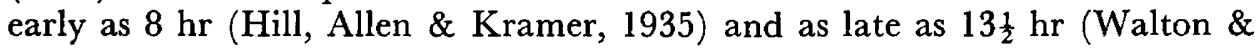
Hammond, 1929) after mating. By contrast, Harper (1963) reported that no ovulation occurred by $10 \mathrm{hr}$ but that $50 \%$ of the ovulations occurred between $10 \frac{1}{2}$ and $10 \frac{3}{4} \mathrm{hr}$ and $100 \%$ by $14 \mathrm{hr}$ after an intravenous injection of 25 to 50 i.u. LH.

Laparoscopic observation of ovulation in rabbits has not been reported and, with the exception of the excellent cinematographic observations by Blandau (1955), few have been able to predict ovulation accurately and perform serial observation of follicular morphology near ovulation.

The present paper describes the adaptation of laparoscopy to the observation and timing of follicular development and ovulation in the rabbit.

* Present address: The Population Council, Biomedical Division, The Rockefeller University, New York, N.Y. 10021, U.S.A.

$\dagger$ Address for reprint requests. 


\section{MATERIALS AND METHODS}

Twenty-one, virgin, adult, female rabbits of mixed breeding and 3.4 to $4.6 \mathrm{~kg}$ in body weight were used. They were separately caged for at least 3 weeks before use to preclude the development of pseudopregnancy.

All rabbits were assigned to one of three treatments: Group I, natural mating. Six does were mated two or three times to males of proven fertility. No exogenous gonadotrophins were given; Group II, HCG-induced ovulation. Five does were injected intravenously with 100 i.u. HGG (A.P.L., Ayerst Laboratories); Group III, PMSG-HCG induced ovulation. Ten does were injected intravenously

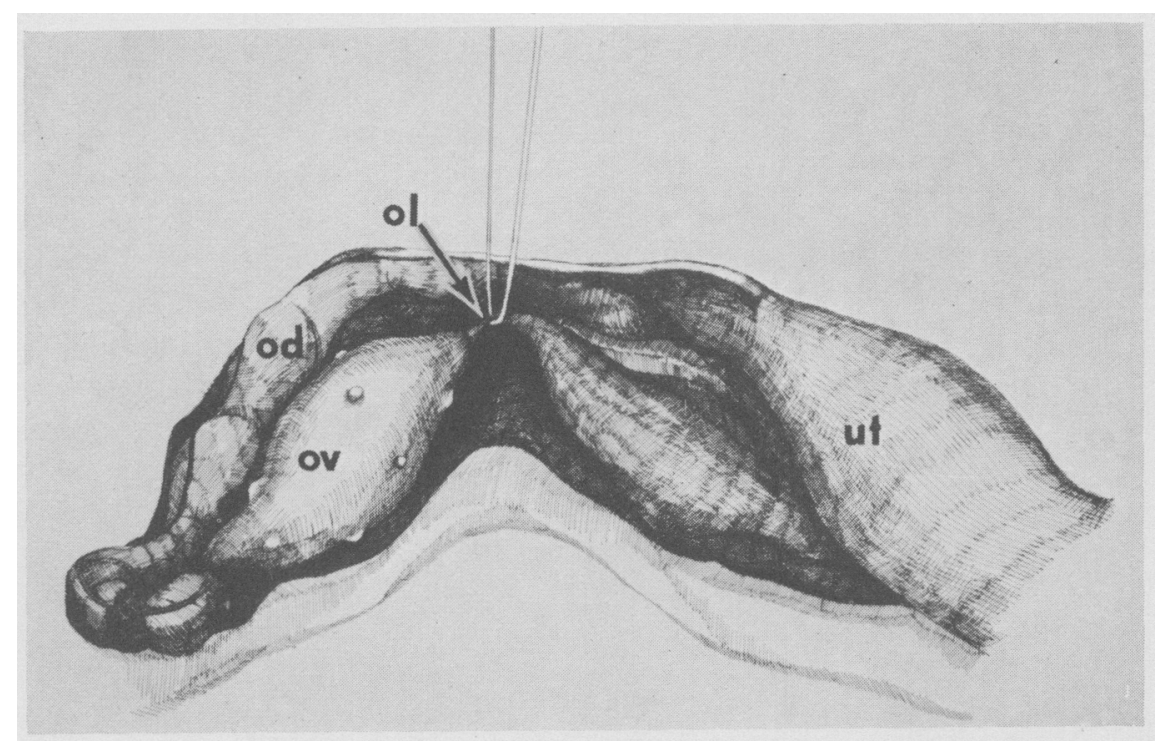

TExT-FIG. 1. Diagrammatic representation of the ovarian suspension technique used to facilitate ovarian observation during laparoscopy in the rabbit (ol = ovarian ligament; od = oviduct; ov = ovary; ut = uterus).

with 100 i.u. HCG 4 days after priming with 100 i.u. PMSG (Lilly Laboratories) intramuscularly.

The first laparoscopic examinations were made 8 to $9 \mathrm{hr}$ after the ovulatory stimulus (mating or HCG) under sodium pentobarbitone anaesthesia.

The laparoscope was a Wolf paediatric $135^{\circ}$ model. The laparoscopic equipment and its use in other species has been previously reported (Dukelow, Jarosz, Jewett \& Harrison, 1971; Jewett \& Dukelow, 1972, 1973; Rawson \& Dukelow, 1973a, b). Abdominal distension by $5 \% \mathrm{CO}_{2} /$ air was required in the rabbit.

For assistance in locating the ovaries, 3-0 gut sutures were threaded through the abdominal wall around the ovarian ligament and back through the wall where they were loosely tied (Text-fig. 1). Manual elevation of the external portion of the sutures made suspension and observation of the ovaries a simple procedure (Pl. 1, Fig. 1). 
Serial observations were continued at intervals of 1 or $2 \mathrm{hr}$. Photographs were taken with a Canon-TL, $35 \mathrm{~mm}$ camera/Ektachrome EHB film at $\frac{1}{8}$ to $\frac{1}{4}$ sec exposure.

The laparoscopic technique described herein was subsequently used in four does from Group I for the counting of the potential implantation sites on Day 6 as well as the observation of the uterine vascularization associated with the site of implantation.

For ease of classification of developing follicles, five types were assigned to an alphabetical system: Type $A$ follicles were large dome-shaped structures with a haemorrhagic appearance at the apex. Type B referred to a large dome-shaped structure without the haemorrhagic appearance. Type $\mathrm{C}$ was smaller, but still elevated above the ovarian surface while Type D was not elevated from the ovarian surface. Type $E$ was used to refer to a follicle not present at the previous observation.

\section{RESULTS}

The total number of follicles, postovulatory follicles and percentage ovulation for the three groups are shown in Tables 1, 2 and 3, respectively. They are classified according to the time interval after ovulatory stimulus.

In Group I (Table 1), the initiation of ovulation was delayed and the

Table 1. Ovulation in rabbits* subjected to natural mating

\begin{tabular}{c|c|c|c}
\hline $\begin{array}{c}\text { Time between } \\
\text { mating and } \\
\text { laparoscopy } \\
\text { (hr) }\end{array}$ & $\begin{array}{c}\text { Total no. of } \\
\text { follicles }\end{array}$ & $\begin{array}{c}\text { No. of } \\
\text { postovulatory } \\
\text { follicles }\end{array}$ & $\begin{array}{c}\% \\
\text { ovulation }\end{array}$ \\
\hline 8 to $8 \frac{1}{2}$ & 74 & 1 & 1.4 \\
10 to $10 \frac{1}{2}$ & 86 & 6 & $7 \cdot 0$ \\
12 to $12 \frac{1}{2}$ & 94 & 14 & $14 \cdot 9$ \\
14 to $14 \frac{1}{2}$ & 99 & 25 & $25 \cdot 3$ \\
\hline
\end{tabular}

* Group I, six does.

percentage ovulation at 14 to $14 \frac{1}{2} \mathrm{hr}$ was $25.3 \%$, that is, one half that of the other two groups (Text-fig. 2). The mean number of ovulation points per animal, $4 \cdot 2$, was also low.

In Group II, twenty laparoscopic examinations were carried out in five females between 8 and $14 \frac{1}{2} \mathrm{hr}$ after the HCG injection (Table 2). In this group, ovulation started later than in Group III, but as illustrated in Text-fig. 2, both groups ovulated at a similar rate at 14 to $14 \frac{1}{2} \mathrm{hr}$. The number of ovulation points per animal at 8 to $8 \frac{1}{2} \mathrm{hr}$ and 14 to $14 \frac{1}{2} \mathrm{hr}$ were, 0 and $4 \cdot 8$, respectively.

In Group III, forty-three laparoscopic examinations were performed in ten does between 8 and $14 \frac{1}{2} \mathrm{hr}$ after the HCG injection (Table 3). Ovulations were observed at 8 to $8 \frac{1}{2} \mathrm{hr}$ in four out of nine does $(44 \%)$ and at 9 to $9 \frac{1}{2} \mathrm{hr}$ in six out of ten $(60 \%)$. At 10 to $10 \frac{1}{2} \mathrm{hr}$, ovulation had occurred in all ten does. Ovulation rates increased from $6.9 \%$ at 8 to $8 \frac{1}{2} \mathrm{hr}$, to $52.9 \%$ at 14 to $14 \frac{1}{2} \mathrm{hr}$. The mean 
numbers of ovulation points per animal increased from 0.9 at 8 to $8 \frac{1}{2} \mathrm{hr}$ to $10 \cdot 8$ at 14 to $14 \frac{1}{2} \mathrm{hr}$. Superovulation occurred in two animals with nineteen and twenty-three ovulations, respectively.

The results shown above demonstrate a large variation in the time of onset, the duration of ovulation and ovulation rates between groups.

We also observed the moment of rupture of ten follicles in two animals of Group I and three animals of Group III. Preovulatory follicles representing

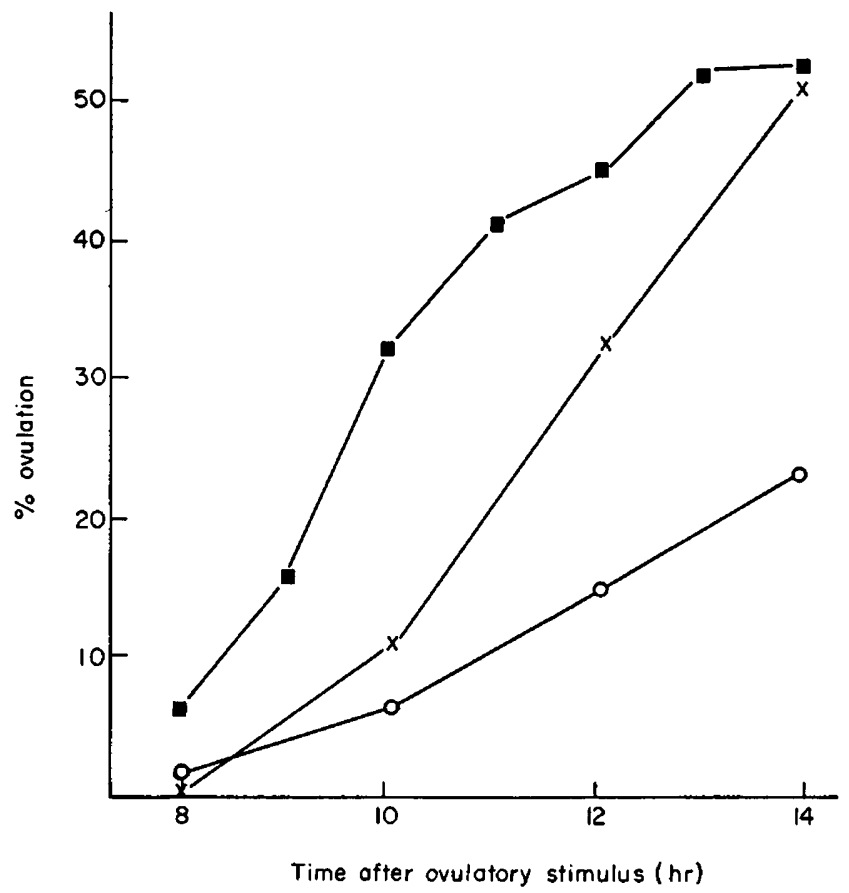

TEXT-FIG. 2. Ovulation rate at various times after an ovulatory stimulus of mating ( 0 ), HGG alone $(x)$ or PMSG and HCG $(\square)$ in rabbits.

various stages of development are illustrated in Pl. 1, Figs 2 and 3(a). Postovulatory sites are visible in Pl. 1, Figs $3(\mathrm{~b})$ and 4 . Occasionally haemorrhagic follicles attained a greater volume than the normally developing mature follicles. Plate 1, Fig. 5 illustrates a cumulus mass adhering to the ovarian surface shortly following follicular rupture. Later (Pl. 1, Fig. 6), the cumulus mass could be seen on the fimbria.

Although a small non-protruding follicle was not defined as a mature follicle

\section{EXPLANATION OF PLATE 1}

FIG. 1. Elevation of the external portion of sutures laparoscopically placed around the ovarian ligaments to facilitate suspension and observation of the ovaries in a rabbit.

Fig. 2. Preovulatory (Type A) follicle. Note the ease of observation of the entire ovarian surface made possible by the suspension procedure.

Fig. 3. Several preovulatory (a) and postovulatory (b) follicles present on the same ovary.

Frg. 4. Large immediately postovulatory follicle.

FIG. 5. Cumulus mass adhering to a postovulatory site.

Fig. 6. Cumulus mass on fimbria. 

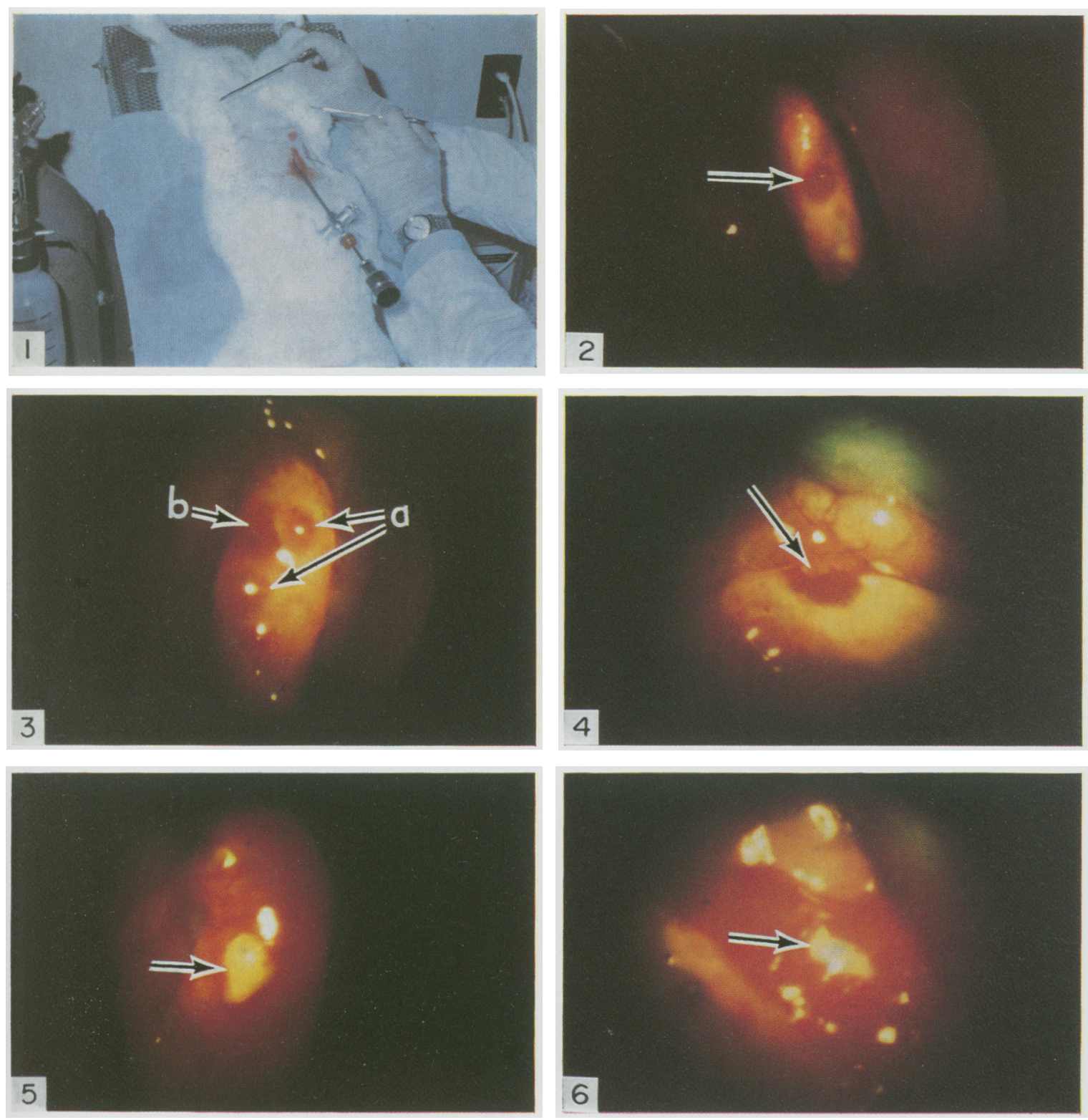

Fining to 100 
Table 2. Ovulation in rabbits* subjected to induced ovulation with 100 i.u. HCG

\begin{tabular}{c|c|c|c}
\hline $\begin{array}{c}\text { Time between } \\
\text { HCG and } \\
\text { laparoscopy } \\
(\mathrm{hr})\end{array}$ & $\begin{array}{c}\text { Total no. of } \\
\text { follicles }\end{array}$ & $\begin{array}{c}\text { No. of } \\
\text { postovulatory } \\
\text { follicles }\end{array}$ & $\begin{array}{c}\% \\
\text { ovulation }\end{array}$ \\
\hline 8 to $8 \frac{1}{2}$ & 34 & 0 & 0 \\
10 to $10 \frac{1}{2}$ & 43 & 5 & $11 \cdot 7$ \\
12 to $12 \frac{1}{2}$ & 44 & 15 & $34 \cdot 1$ \\
14 to $14 \frac{1}{2}$ & 46 & 24 & $52 \cdot 2$ \\
\hline
\end{tabular}

* Group II, five does.

by Walton \& Hammond (1929), we observed laparoscopically that in many animals this type of follicle had developed into a large mature follicle during the serial examinations ranging from 8 to $14 \frac{1}{2} \mathrm{hr}$ after the induction of ovulation.

As previously described by Walton \& Hammond (1929), and Hill et al. (1935), the major developments of follicles about to ovulate take place about $2 \mathrm{hr}$ before rupture. In the present studies, the blood supply increased remarkably on the follicular surface and extravasation of blood was observed during the last $30 \mathrm{~min}$ before rupture.

Laparoscopy of four pregnant rabbits on Day 6 revealed a total of twentytwo visible blastocysts, equally distributed in the uterine horns. Immediately

Table 3. Ovulation in rabbits* subjected to induced ovulation with 100 i.u. PMSG and 100 i.u. HCG

\begin{tabular}{c|c|c|c|c}
\hline $\begin{array}{c}\text { Time between } \\
\text { HCG and } \\
\text { laparoscopy } \\
\text { (hr) }\end{array}$ & $\begin{array}{c}\text { No. of } \\
\text { does }\end{array}$ & $\begin{array}{c}\text { Total no. of } \\
\text { follicles }\end{array}$ & $\begin{array}{c}\text { No. of } \\
\text { postovulatory } \\
\text { follicles }\end{array}$ & $\begin{array}{c}\% \\
\text { ovulation }\end{array}$ \\
\hline 8 to $8 \frac{1}{2}$ & 9 & 116 & 8 & $6 \cdot 9$ \\
9 to $9 \frac{1}{2}$ & 5 & 66 & 10 & $15 \cdot 2$ \\
10 to $10 \frac{1}{2}$ & 9 & 128 & 43 & $33 \cdot 7$ \\
11 to $11 \frac{1}{2}$ & 4 & 61 & 25 & $41 \cdot 0$ \\
12 to $12 \frac{1}{2}$ & 7 & 110 & 49 & $44 \cdot 6$ \\
13 to $13 \frac{1}{2}$ & 4 & 65 & 34 & 52.3 \\
14 to $14 \frac{1}{2}$ & 5 & 102 & 54 & $52 \cdot 9$ \\
\hline
\end{tabular}

* Group III.

after laparoscopy, the animals were killed and the blastocysts flushed from the horns. Twenty-three blastocysts were recovered, verifying the applicability of laparoscopy to achieving a close estimate of the number of Day 6 blastocysts.

\section{DISCUSSION}

The present findings are in general agreement with the laparotomy-autopsy data of Walton \& Hammond (1929) and Harper (1961, 1963), and the cinemicrographic observations of Hill et al. (1935).

Harper (1963) reported that no ovulation was observed by $10 \mathrm{hr}, 50 \%$ ovula- 
tion was observed between $10 \frac{1}{2}$ and $10 \frac{3}{4} \mathrm{hr}$ and $100 \%$ by $14 \mathrm{hr}$ after the HCG injection.

The earlier onset of ovulation observed at 8 to $8 \frac{1}{2} \mathrm{hr}$ after HCG injection in the present Group III was probably due to the regimen of ovulation induction (PMSG 100 i.u., HCG 100 i.u.).

The ovulation rates in the present studies were lower than the percentage ovulation in the time periods between injection of LH and autopsy reported by Harper (1963). The mean number of total follicles in Group I and Group II, however, did not differ from his data. Our data do indicate an increase in the slope of the ovulation curve (Text-fig. 2) for animals receiving HCG, indicating earlier ovulation. This was of greatest magnitude in animals subjected to a superovulation regimen, a factor to be considered in reproduction assay techniques involving timed ovulations.

An interesting observation on the development of the follicle towards ovulation was that often the Type B and C follicles at one examination period had ovulated before those follicles with a Type A appearance at the initial examination. Whether this is due to follicular atresia of the Type A follicles is not known.

The results of the laparoscopic examination of the pregnant rabbits reveal a high degree of accuracy in the quantification of potential implantation sites. These observations also suggest that the anaesthesia and laparoscopic technique had no effect on the fertilizability of the ovum since the pregnant animals had been previously subjected to laparoscopy at the time of ovulation. These results are similar to those reported after laparoscopy in non-human primates (Rawson \& Dukelow, 1973a).

A significant finding of this study relates to the relative ease of the technical manipulation required for laparoscopy in the rabbit. With the suspension of the ovarian ligament, the entire ovary easily came into view and could be quickly and easily observed. The results serve to emphasize the usefulness of the laparoscopic techniques for studies necessitating ovulation detection and timing, diagnosis of pregnancy and enumeration of $C L$ and for studies in which oviducal and uterine manipulations such as ligations or sampling are indicated.

\section{ACKNOWLEDGMENTS}

The authors wish to express their appreciation to Dr Nahid Pahlavan for her excellent assistance. This work was supported by NIH Contract No. 70-2061 and NIH Research Career Development Award No. 1-K4-HD36, 306. Michigan Agricultural Experiment Station Journal Article Number 6496.

\section{REFERENGES}

Balin, H., Wan, L. S. \& Rajan, R. (1969) Experimental application of endoscopy. Clin. Obstet. Gynec. 12,534 .

Blandau, R. J. (1955) Ovulation in the living albino rat. Fert. Steril. 6, 391.

Dukelow, W. R., Jarosz, S. J., Jewett, D. A. \& Harrison, R. M. (1971) Laparoscopic examination of the ovaries in goats and primates. Lab. Anim. Sci. 21, 594.

Harper, M. J. K. (1961) The time of ovulation in the rabbit following the injection of luteinizing hormone. 7. Endocr. 22, 147. 
HARPER, M. J. K. (1963) Ovulation in the rabbit: the time of follicular rupture and expulsion of the eggs, in relating to injection of luteinizing hormone. F. Endocr. 26, 307.

Hill, R. T., Allen, E. \& Kramer, T. G. (1935) Cinematographic studies of rabbit ovulation. Anat. Rec. 63, 239.

JewEtT, D. A. \& Dukelow, W. R. (1972) Serial observations of follicular morphology near ovulation in Macaca fascicularis. F. Reprod. Fert. 31, 287.

JewetT, D. A. \& Dukelow, W. R. (1973) Follicular observation and laparoscopic aspiration techniques in Macaca fascicularis. 7. med. Primatol. 2, 108.

Rawson, J. M. R. \& Dukelow, W. R. (1973a) Effect of laparoscopy and anesthesia on ovulation, conception, gestation and lactation in a Macaca fascicularis. Lab. Primate Newsl. 12, 4.

Rawson, J. M. R. \& Dukelow, W. R. (1973b) Observation of ovulation in Macaca fascicularis. $\mathcal{F}$. Reprod. Fert. 34, 187.

Semm, K. (1969) Gynaecological pelviscopy and its instrumentarium. Acta europ. fertil. 1, 81.

Walton, A. \& Hammond, J. (1929) Observations on ovulation in the rabbit. Br. F. exp. Biol. 6, 190. 